\title{
Important Consideration in Choosing Antipsychotics in the Treatment of Patients with 22q11.2 Deletion Syndrome: Risk of Convulsion
}

\author{
Seo-Hyun Choi, Sang-Gu Kang, Hee-Yeon Kim, Hye-Young Kim, Jae-Nam Bae, Jung-Sub Lee, Won-Hyoung Kim \\ Department of Psychiatry, Inha University Hospital, Incheon, Korea
}

\begin{abstract}
The prevalence of epilepsy and psychosis in 22q11.2 deletion syndrome (22q11.2DS) is higher than in the general population. Recent study on adults with 22q11.2DS reported that the most common trigger for provoked seizures was the use of antipsychotics and antidepressants. In this paper, blonaserin was used because aripiprazole, quetiapine, paliperidone were not effective. The patient had convulsion on the fourth day of taking blonaserin. Neurological and cardiac examination was carried out, and lamotrigine was added at the advice of neurologist. Than the patient didn't have any convulsions and the symptoms gradually improved. When treating patients with 22q11.2DS, the medicine should be chosen carefully, and the patient should be observed closely, paying attention to the possibility of convulsions.
\end{abstract}

KEY WORDS: DiGeorge syndrome; Pschotic disorder; Seizure; Aantipsychotic agents.

\section{INTRODUCTION}

A $22 q 11.2$ deletion syndrome (22q11.2DS) is the most common deletion syndrome in humans with an estimated frequency of $1: 2,000$ to $1: 4,000$ of live births [1]. More than 180 clinical features have been described, such as cardiovascular malformations, palatal anomalies, immune deficiency, and dysmorphic facial features [2-4]. Neuropsychiatric disorders have frequently been reported $[5,6]$. Some reports have highlighted the high frequency of schizophrenia among individuals with the $22 q 11.2$ deletion compared to the general population $[7,8]$.

Although psychosis and epilepsy may coexist in adult patients with 22q11.2DS, few reports have discussed the interrelation between schizophrenia and seizure. This paper reports a case of 22q11.2DS in an adult patient, who

Received: September 7, 2018 / Revised: December 6, 2018

Accepted: December 21, 2018

Address for correspondence: Won-Hyoung Kim

Department of Psychiatry, Inha University Hospital, 27 Inhang-ro,

Jung-gu, Incheon 22332, Korea

E-mail: ckgodman@hanmail.net

ORCID: https://orcid.org/0000-0002-6650-3685 had a seizure during the treatment of schizophrenia.

\section{CASE}

A 25-year-old woman was admitted to hospital for her first episode of psychosis. The patient was born via a normal vaginal delivery after an uncomplicated full-term pregnancy. The tetralogy of Fallot was diagnosed at 9 months and treated surgically at the age of 1 and 3 years. She had no seizure history until admission and no family history of epilepsy or psychiatric disorders.

At the time of admission, she had swollen eyelids, short palpebral fissures, flat cheeks, a bulbous nose tip, broad nasal root, and low-set ears. Her vital signs were stable and the medical and neurological examination revealed no abnormalities. A mental status examination revealed a psychotic state including paranoid delusions, a delusion of reference, and thought control. In addition, she stated that she heard unfamiliar voices trying to communicate with her continuously. She presented with psychomotor agitation, and a lack of insight. Her Positive and Negative Syndrome Scale (PANSS) score was 96 based on these symptoms.

(ㄷ) This is an Open-Access article distributed under the terms of the Creative Commons Attribution Non-Commercial License (http://creativecommons.org/licenses/by-nc/4.0) which permits unrestricted non-commercial use, distribution, and reproduction in any medium, provided the original work is properly cited. 
The neuropsychological assessment revealed a full-scale intelligence quotient of 66 on the Korean Wechsler Adult Intelligence Scale. Her blood count was normal without any signs of infection. The serum calcium level and serum phosphorous level were normal. The thyroid function tests and intact parathyroid hormone were normal. An electrocardiogram revealed a normal sinus rhythm but possible right ventricular hypertrophy. Electroencephalography (EEG) showed generalized fast activities but within the normal limits. The 22q11.2DS deletion was confirmed using a fluorescence in situ hybridization probe. Based on these findings, the patient was diagnosed with 22q11.2DS, mild mental retardation, and schizophrenia.

Thirty milligrams of aripiprazole and $800 \mathrm{mg}$ of quetiapine was tried at first and then switched to $30 \mathrm{mg}$ of olanzapine and $400 \mathrm{mg}$ of amisulpride but the symptoms didn't improve. The psychiatrist used olanzapine $30 \mathrm{mg}$ and paliperidone $9 \mathrm{mg}$ for 2 weeks, but the symptoms persisted. Therefore, paliperidone was changed to $8 \mathrm{mg}$ of blonaserin.

On the fourth day that blonaserin was administered, the patient fell to the ground with generalized shaking of her extremities for 20 seconds. At that time, blonaserin was discontinued, and cardiology and neurology consultations were requested. The ECGs performed after the events revealed an incomplete right bundle branch block and prolonged QTc (483 mc). A sleep deprived EEG indicated localized cerebral dysfunction and bilateral temporal areas. The magnetic resonance imaging revealed multiple iso and high signal intense lesions in the bilateral periventricular white matter and subcortical white matter. The neurologist recommended the addition of lamotrigine to reduce the likelihood of seizure activity and the careful prescription of antipsychotics. She had three more absence-like seizures on five days after the first seizure. The neurologist recommended that lamotrigine be increased to $75 \mathrm{mg}$ twice a day. After lamotrigine was increased, there were no more seizures, and the psychotic symptoms improved. The patient was discharged 10 days after remaining seizure-free on olanzapine $30 \mathrm{mg}$ and lamotrigine $150 \mathrm{mg}$ daily.

\section{DISCUSSION}

The effectiveness and safety of antipsychotics in the treatment of psychosis associated with 22q11.2DS are not well established. 22q11.2DS is relatively unresponsive to currently used antipsychotic drugs [9]. Quetiapine and olanzapine appear to be efficacious in 22q11.2DS patients with schizophrenia because they are in idiopathic schizophrenia, whereas risperidone may be less effective [10-12]. Clozapine has been shown to reduce schizophrenia symptoms and hospitalizations as effectively in 22q11.2DS patients as it does in idiopathic schizophrenia, and at a lower average dose. On the other hand, neurological side effects with antipsychotic therapy tend to increase in 22q11.2DS patients and with clozapine in particular. These include generalized tonic-clonic seizures, focal seizures, myoclonus, rigidity, and tremors, with seizure being the most severe and most common [13,14].

The prevalence of epilepsy and acute symptomatic seizures in adults with $22 \mathrm{q} 11.2 \mathrm{DS}$ is higher than in the general population $[7,15]$. A recent study on adults with this condition reported that the most common trigger for provoked seizures was the use of antipsychotics and antidepressants, even though a history of hypocalcemia was also common [16]. The incidence of seizure reported from US Food and Drug Administration approval trials was highest with clozapine, olanzapine, and quetiapine compared to a placebo. Only a slight increase was observed with ziprasidone, aripiprazole and risperidone [17]. In epileptic patients, risperidone has a low risk of inducing seizure activity [18]. In this case, it is presumed the convulsion occurred by adding blonaserin to the high capacity of antipsychotics. Although recent studies have shown that blonaserin prevents convulsion, but in this case blonaserin increases the potency of antipsychotics, and did not prevent convulsion [19]. After the convulsion was stopped, the previously used olanzapine was again used as $30 \mathrm{mg}$, but seizure did not occur again and the psychotic symptom also improved. Careful observation is always needed because high doses of psychotic drugs are risk factors for convulsion in 22q11.2DS [17].

For the seizure risk, a detailed history, full neurological examination and neurologist consultation to assist in the selection of the most appropriate anticonvulsant or augmentation agent is recommended in 22q11.2DS [18]. After seizure events, antipsychotics should be switched to others or stopped. Previous papers have reported similar cases. Additional monitoring, such as ECG or EEG, should be repeated at consecutive intervals during treatment in the 22q11.2DS [20]. 
When treating schizophrenia patients with 22q11.2DS, the high dose of antipsychotic drugs should be chosen carefully, and the patients should be observed closely, paying attention to the possibility of convulsions. This is important for preventing potential adverse neurological events.

\section{Acknowledgments}

This work was supported by an Inha University Research Grant.

\section{Conflicts of Interest}

No potential conflict of interest relevant to this article was reported.

\section{Author Contributions}

Conceptualization: Won-Hyoung Kim, Seo-Hyun Choi. Investigation: Seo-Hyun Choi, Sang-Gu Kang. Resources: Won-Hyoung Kim, Seo-Hyun Choi. Supervision: Hee-Yun Kim, Hye-Young Kim, Jae-Nam Bae, and Jung-Sub Lee. Writing - original draft: Seo-Hyun Choi. Writing - review \& editing: Won-Hyoung Kim.

\section{ORCID}

Seo-Hyun Choi https://orcid.org/0000-0002-2726-5610 Sang-Gu Kang https://orcid.org/0000-0003-0824-9022 Hee-Yeon Kim https://orcid.org/0000-0002-6766-5969 Hye-Young Kim https://orcid.org/0000-0002-2313-8892 Jae-Nam Bae https://orcid.org/0000-0002-5024-6231 Jung-Sub Lee https://orcid.org/0000-0001-5585-0334 Won-Hyoung Kim https://orcid.org/0000-0002-6650-3685

\section{REFERENCES}

1. Hoeffding LK, Trabjerg BB, Olsen L, Mazin W, Sparsø T, Vangkilde A, et al. Risk of psychiatric disorders among individuals with the 22q11.2 deletion or duplication: a danish nationwide, register-based study. JAMA Psychiatry 2017;74: 282-290.

2. Shprintzen RJ. Velo-cardio-facial syndrome: a distinctive behavioral phenotype. Ment Retard Dev Disabil Res Rev 2000;6:142-147.

3. Shprintzen RJ, Higgins AM, Antshel K, Fremont W, Roizen N, Kates W. Velo-cardio-facial syndrome. Curr Opin Pediatr 2005; 17:725-730.

4. Shprintzen RJ. Velo-cardio-facial syndrome: 30 Years of study. Dev Disabil Res Rev 2008;14:3-10.

5. Kim SY, Um YH, Lim SC, Jeong JH. Limbic encephalitis manifesting as selective amnesia and seizure-like activity: a case report. Clin Psychopharmacol Neurosci 2018;16:109-113.
6. Aytuluk HG, Simsek T, Yilmaz M, Turan AZ, Saracoglu KT. Can propofol lead to an increase in seizure threshold over the course of electroconvulsive therapy? Clin Psychopharmacol Neurosci 2019;17:523-530.

7. Schneider M, Debbané M, Bassett AS, Chow EW, Fung WL, van den Bree M, et al. Psychiatric disorders from childhood to adulthood in 22q11.2 deletion syndrome: results from the International Consortium on Brain and Behavior in 22q11.2 Deletion Syndrome. Am J Psychiatry 2014;171:627-639.

8. Jolin EM, Weller RA, Jessani NR, Zackai EH, McDonaldMcGinn DM, Weller EB. Affective disorders and other psychiatric diagnoses in children and adolescents with $22 q 11.2$ Deletion Syndrome. J Affect Disord 2009;119:177-180.

9. Vogels A, Verhoeven WM, Tuinier S, DeVriendt K, Swillen A, Curfs LM, et al. The psychopathological phenotype of velo-cardio-facial syndrome. Ann Genet 2002;45:89-95.

10. Müller UJ, Fellgiebel A. Successful treatment of long-lasting psychosis in a case of 22q11.2 deletion syndrome. Pharmacopsychiatry 2008;41:158-159.

11. Verhoeven WM, Egger JI. Atypical antipsychotics and relapsing psychoses in 22q11.2 deletion syndrome: a long-term evaluation of 28 patients. Pharmacopsychiatry 2015;48:104110.

12. Dori N, Green T, Weizman A, Gothelf D. The effectiveness and safety of antipsychotic and antidepressant medications in individuals with 22q11.2 deletion syndrome. J Child Adolesc Psychopharmacol 2017;27:83-90.

13. Gladston S, Clarke DJ. Clozapine treatment of psychosis associated with velo-cardio-facial syndrome: benefits and risks. J Intellect Disabil Res 2005;49:567-570.

14. Yacoub A, Aybar M. Response to clozapine in psychosis associated with velo-cardio-facial syndrome. Psychiatry (Edgmont) 2007:4:14.

15. Ryan AK, Goodship JA, Wilson DI, Philip N, Levy A, Seidel H, et al. Spectrum of clinical features associated with interstitial chromosome 22q11 deletions: a European collaborative study. J Med Genet 1997;34:798-804.

16. Wither RG, Borlot F, MacDonald A, Butcher NJ, Chow EWC, Bassett AS, et al. 22q11.2 deletion syndrome lowers seizure threshold in adult patients without epilepsy. Epilepsia 2017; 58:1095-1101.

17. Alper K, Schwartz KA, Kolts RL, Khan A. Seizure incidence in psychopharmacological clinical trials: an analysis of Food and Drug Administration (FDA) summary basis of approval reports. Biol Psychiatry 2007;62:345-354.

18. Hulvershorn LA, Madou MR, Weis JR, Coffey B. First-episode psychosis in an adolescent with seizure disorder and tetralogy of Fallot. J Child Adolesc Psychopharmacol 2009;19:307311.

19. Yokota K, Tatebayashi H, Matsuo T, Shoge T, Motomura H, Matsuno $\mathrm{T}$, et al. The effects of neuroleptics on the GABA-induced Cl-current in rat dorsal root ganglion neurons: differences between some neuroleptics. Br J Pharmacol 2002;135: 
1547-1555.

20. Correll CU, Penzner JB, Parikh UH, Mughal T, Javed T, Carbon $\mathrm{M}$, et al. Recognizing and monitoring adverse events of second-generation antipsychotics in children and adolescents. Child Adolesc Psychiatr Clin N Am 2006; 15:177-206. 